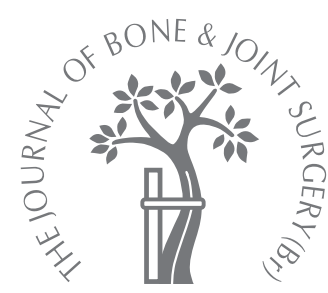

L. Young,

S. Duckett,

A. Dunn

From the West

Suffolk Hospital,

Bury St Edmunds,

England

\title{
The use of the cemented Exeter Universal femoral stem in a District General Hospital
}

\author{
A MINIMUM TEN-YEAR FOLLOW-UP
}

- L. Young, MRCS, Specialist Registrar

S. Duckett, MRCS, Specialist Registrar

A. Dunn, FRCS(Orth),

Consultant Orthopaedic

Surgeon

Department of Trauma and

Orthopaedics

West Suffolk Hospital, Hardwick Lane, Bury St Edmunds, Suffolk

IP33 2OZ, UK.

Correspondence should be sent to Mr A. Dunn; e-mail:

Andrew.dunn@wsh.nhs.uk

(C)2009 British Editorial Society of Bone and Joint Surgery doi:10.1302/0301-620X.91B2. $20473 \$ 2.00$

$J$ Bone Joint Surg $[\mathrm{Br}]$ 2009;91-B:170-5. Received 12 November 2007 Accepted after revision 15 October 2008

We describe the survivorship of the Exeter femoral component in a District General Hospital. Between 1994 and 1996, 230 Exeter Universal cemented femoral components were implanted in 215 patients who were reviewed at a mean of 11.2 years (10 to 13). We used one acetabular implant, the Elite Ogee component, in 218 of the 230 hips.

During the period of this study 76 patients $(79$ hips) died. Of the remaining 139 patients (151 hips), 121 were able to attend for radiological analysis at a minimum of ten years. One patient was lost to follow-up.

No femoral component was revised for aseptic loosening. Three hips were revised for deep infection and six acetabular components required revision, four for loosening and two for recurrent dislocation. Taking the 'worst-case scenario' including the one patient lost to follow-up, the overall survival rate was $94.4 \%$ at 13 years.

Our results confirm excellent medium-term results for the Exeter Universal femoral component, implanted in a general setting. The excellent survival of this femoral component, when used in combination with the Ogee acetabular component, suggests that this is a successful pairing.

The first Exeter Hip implant (Howmedica International Ltd, London, United Kingdom) was used clinically in $1970 .{ }^{1}$ It had the unique design of a collarless, double-tapered, polished femoral stem. The surface of the femoral component was changed between 1976 and 1985 to a matt surface, but this showed inferior results, ${ }^{2,3}$ resulting in a return to the polished surface in 1986. The Exeter Universal femoral component (Howmedica International Ltd) was introduced in 1988 and incorporated modularity, stiffening of the shoulder by the addition of metal, and a more tapered stem in the anteroposterior configuration, which was extended to the base of the neck (Fig. 1).

The long-term results with the original design have been good, ${ }^{1}$ and the originating centre has reported excellent results for the modified component ${ }^{4}$ at a mean follow-up of 8.9 years, using a variety of different acetabular components. A teaching hospital has recently presented similar results ${ }^{5}$ with a mean follow-up of 12.7 years. Again, several different acetabular components were used. The Swedish hip registry ${ }^{6}$ has also reported good results for the Exeter Universal femoral component, although only in the last five years has it been able to distinguish between failure of the femoral and acetabular components.
Our aim was to examine the results of the use of the Exeter Universal femoral component in a District General Hospital, where the operations were performed by various grades of surgeon, with a minimum follow-up of ten years. We also aimed to establish the outcome of the combination of the Exeter femoral component and the Elite Ogee acetabular component (DePuy International Ltd, Leeds, United Kingdom), which was used in most of the patients in our series.

\section{Patients and Methods}

Between March 1994, when the Exeter total hip replacement (THR) was first used at this hospital, and December 1996, we performed 230 consecutive primary THRs, using the Exeter Universal femoral component. These were undertaken in 215 patients, six of whom underwent simultaneous bilateral THR and nine staged bilateral THR. The operations were performed by two consultants in 154 hips $(67.0 \%)$, their registrars in 46 hips $(20.0 \%)$, staff grade surgeons in 24 hips $(10.4 \%)$ and junior trainees under varying levels of supervision in six hips $(2.6 \%)$.

Of the 230 THRs, 142 were performed in women. The mean age of the patients at the time of operation was 68.9 years (44 to 89). 


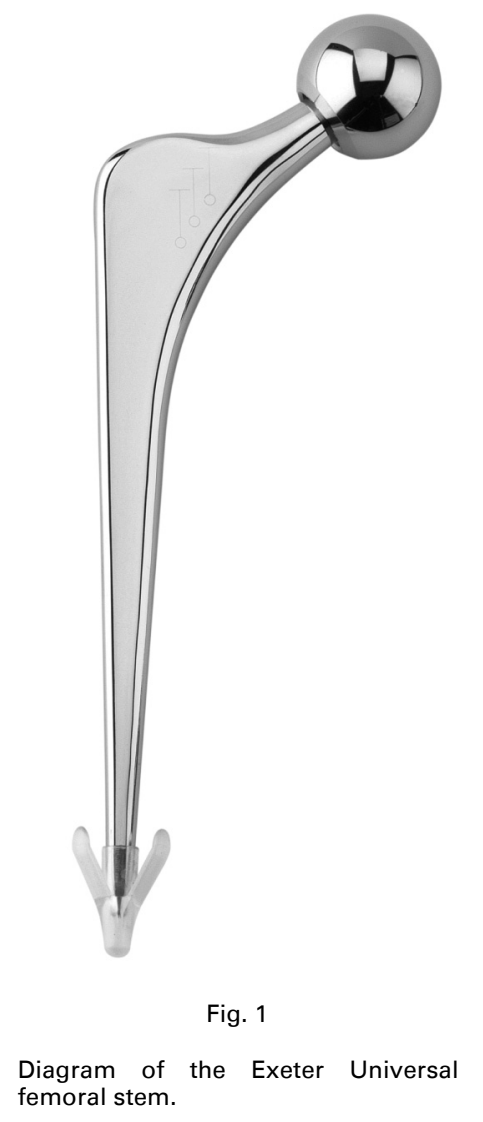

The age distribution is shown in Table I. The mean weight was $71.5 \mathrm{~kg}$ (41 to 114), the mean height was $166.0 \mathrm{~cm}$ (124 to 195 ), and the mean body mass index was 25.8 (15.8 to 39.4 ). No patient was excluded. The pre-operative diagnoses of the hips are listed in Table II.

Operative technique. We used the Exeter Universal femoral component with a $26 \mathrm{~mm}$ diameter stainless steel head in 228 patients (99\%) and $28 \mathrm{~mm}$ in the remainder. In 218 hips $(94.8 \%)$ an Elite Ogee acetabular component was used. The uncemented Universal Biomet acetabular component (Biomet UK Ltd, Bridgend, United Kingdom) was used in the other 12 hips for clinical reasons including young and high demand patients. CMW cement (CMW Laboratories Dentsply, Exeter, United Kingdom) was used in 228 hips and Palacos cement (Schering-Plough Ltd, Welwyn Garden City, United Kingdom) in the remaining two.

In all, 228 THRs were implanted using the posterior approach and two using the direct lateral approach. The acetabulum was prepared by removing the osteophytes from the acetabular margin followed by the use of sequential hemispherical reamers to enlarge the cavity before creating multiple key-holes and using high-pressure lavage. The Elite Ogee components were cemented in place using standard viscosity CMW 1 cement with gentamicin, which was pressurised using a swab in a glove. Femoral preparation was carried out using sequential broaches, curettage,
Table I. Age distribution of the 215 patients undergoing total hip replacement

\begin{tabular}{lc}
\hline Age of patients at operation (yrs) & Number of patients \\
\hline 40 to 49 & 7 \\
50 to 59 & 26 \\
60 to 69 & 68 \\
70 to 79 & 85 \\
80 to 89 & 29 \\
\hline
\end{tabular}

Table II. Diagnosis in the 230 hips

\begin{tabular}{lc}
\hline Diagnosis & Number of hips \\
\hline Primary osteoarthritis & 195 \\
Rheumatoid arthritis & 14 \\
Avascular necrosis & 6 \\
Previous fracture & 13 \\
Ankylosing spondylitis & 2 \\
\hline
\end{tabular}

non-pressurised lavage and drying. A Hardinge cement restrictor (Corin, Cirencester, United Kingdom) was inserted $16 \mathrm{~cm}$ distal to the tip of the greater trochanter. Low-viscosity (CMW 3) cement was mixed in an open bowl, and inserted retrogradely using a disposable cement syringe and second-generation cementing techniques. In two THRs Palacos cement with gentamicin was used for both the femoral and acetabular components although the reasons for this preference were not documented.

All the initial clinical and operative details were collected prospectively and recorded on a database. Clinical evaluation was by a modified Harris Hip score (HHS). ${ }^{7}$

Radiological analysis. Radiography was performed postoperatively and at the five- and ten-year review. All the radiographs were examined independently by the three authors using recognised assessment techniques as recommended by Johnston et $\mathrm{al}^{8}$ and more recent studies which have made comparisons with previous studies on the Exeter femoral component. The cementing technique was assessed using the grading of Barrack, Mulroy and Harris ${ }^{9}$ in the zones of Gruen, McNeice and Amstutz. ${ }^{10}$ Alignment was assessed directly from the films, and subsidence of $0.1 \mathrm{~mm}$ using the greater trochanter, the proximolateral cement mantle and the prosthesis as landmarks. ${ }^{5}$ Radiolucent lines were analysed according to the definition of Kobayashi et al. ${ }^{11}$ Proximomedial resorption and remodelling of the femur were assessed using the criteria described by Engh, Bobyn and Glassman ${ }^{12}$ which were originally applied to uncemented prostheses. The radiographs were also examined for diaphyseal cortical hypertrophy, fractures of the cement mantle, calcar resorption and cystic changes. Heterotopic ossification was assessed using the grading of Brooker et al. ${ }^{13}$

The acetabular component was examined for demarcation around the cement mantle as described by DeLee and Charnley. ${ }^{14}$ The uncemented acetabular components were 


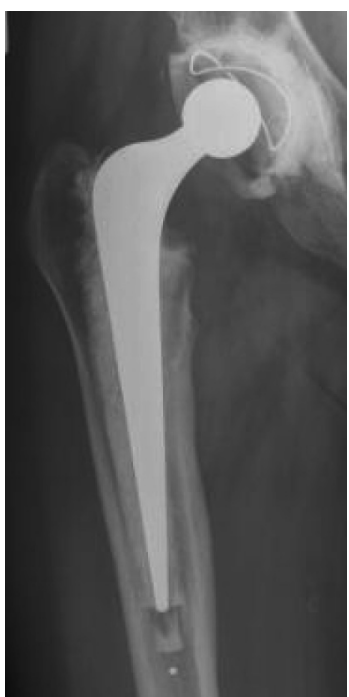

Fig. 2

Radiograph showing diaphyseal hypertrophy, a cement mantle of Barrack grade $C^{9}$ and a grade 2 loss of calcar height. $^{12}$

assessed for wear using the techniques described by Latimer and Lachiewicz. ${ }^{15}$

Statistical analysis. Survival was reported using a life-table method as recommended by Murray, Carr and Bulstrode. ${ }^{16}$ Statistical analysis was undertaken by GraphPad Prism version 5.0 software (GraphPad Software Inc., San Diego, California), and $95 \%$ confidence intervals (CI) were calculated using the Greenwood method.

\section{Results}

Of the 215 patients (230 hips), 76 (79 hips) had died at ten years, giving a mortality of $35 \%$, which is lower than that of comparable studies. ${ }^{4,5}$ Two patients died within the acute post-operative period, one from a pulmonary embolus 14 days after surgery and one from myocardial infarction 12 days post-operatively. In the remaining patients the cause of death was thought to be unrelated to the surgery. The deceased patients' records were examined along with their most recent radiographs, and none was found to have undergone a revision of either component since their last follow-up appointment. Of the remaining 139 patients (151 hips), 121 (121 hips) attended for radiological follow-up. The others had either moved away or were too infirm to attend. Those who were unable to attend for radiography were either sent a postal questionnaire or contacted by telephone. None had undergone any revision surgery, which was also verified by their general practitioner. Only one patient, who failed to attend for follow-up from six months after operation, has been lost to follow-up.

The mean follow-up of the surviving patients was 11.2 years (10 to 13 ). Pre-operatively, the mean modified HHS
Table III. The Brooker grade ${ }^{13}$ of heterotopic ossification in the 121 hips available for radiological review

\begin{tabular}{lc}
\hline Brooker grade & Number of hips \\
\hline O & 80 \\
I & 27 \\
II & 2 \\
III & 10 \\
IV & 2 \\
\hline
\end{tabular}

for pain was 5.2 (0 to 40) and the mean function score was 14.7 (10 to 44 ). At ten years the mean modified HHS for pain was 38.2 ( 0 to 44 ) and mean function score was 34.1 ( 8 to 47 ). There is no physical examination component to the modified HHS so this could not be analysed. The two patients who reported pain scores $\leq 10$ at review had multiple medical co-morbidities, but no concomitant radiological changes. Of the 17 patients with pain scores $\leq 20$, three had femoral components which had been inserted in $>3^{\circ}$ of varus, and one had diaphyseal hypertrophy; none of these changes was progressive. No other corresponding radiological changes were identified to explain the low scores. Most patients had common medical co-morbidities associated with advancing age such as dementia or being bed-ridden and, therefore, found it difficult to answer the questions. Radiological findings. At a minimum follow-up of ten years, 121 paired anteroposterior and lateral radiographs were available for review. The assessment of cementing showed that 60 hips were in Barrack grade A, 53 in grade $B$ and eight in grade C. A total of 79 hips $(65.3 \%)$ was inserted within $2^{\circ}$ of varus or valgus, with no significantly different change in alignment over ten years. Subsidence up to $3 \mathrm{~mm}$ at the cement-prosthesis interface was noted in all hips with an apparent relationship between subsidence and Barrack grading which did not reach statistical significance. Grade A hips appeared to subside less than grade $\mathrm{C}$ hips. No migration at the cement-bone interface was observed in any case. A fracture of the cement mantle was seen in one hip with no apparent history of trauma. The radiological findings were not progressive and the patient did not report any concern about worsening pain or diminishing function.

Radiolucent lines were seen in 15 hips $(12.4 \%)$, but these did not exceed more than $40 \%$ of the cement-bone interface in any hip. Progressive lines were seen in two hips within the first five years of surgery but then stabilised at between five and ten years.

Resorptive bone remodelling changes with rounding off at the proximal femoral neck combined with the loss of medial cortical density extending to the level of the lesser trochanter (grade 2) were noted in ten hips with the remainder being grade 0 or grade 1 . Distal cortical hypertrophy was noted in 14 hips $(11.6 \%)$, ten of which were found to have grade-B or grade-C cementation (Fig. 2). Femoral 


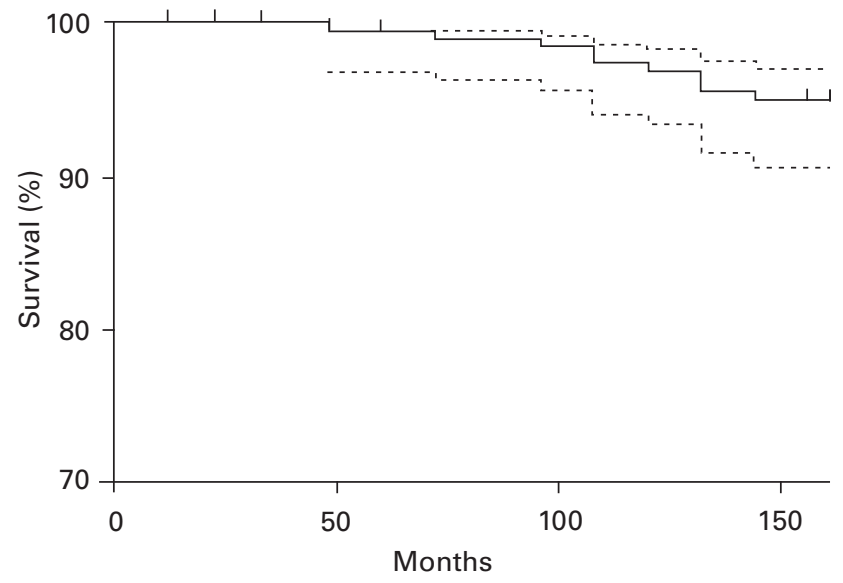

Fig. 3

Graph showing survivorship of the femoral component with revision for any cause as the endpoint.

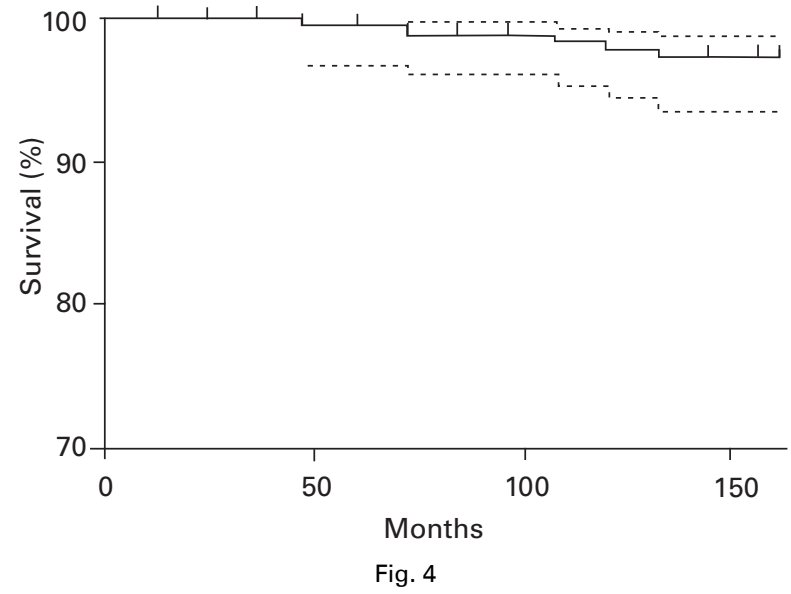

Graph showing survivorship of the Elite Ogee acetabular component with revision for aspects loosening as the endpoint.

osteolysis was not observed on any of the radiographs reviewed. Heterotopic ossification based on the classification of Brooker et $\mathrm{al}^{13}$ is summarised in Table III.

Acetabular radiolucent lines. These were seen in 50 $(41.3 \%)$ of the THRs, but affected all three zones in only $2(1.7 \%)$. No migration of the acetabular component was identified and no focal pelvic osteolysis was seen in any hip. Revisions. No femoral component was revised because of aseptic loosening and no breakages of the femoral component were found. A total of six of 121 acetabular components was revised $(5.0 \%)$ of which five were Elite Ogee components. Two of these revisions were performed for recurrent dislocation and four for aseptic loosening. In all cases the femoral components were found to be well-fixed, and were left in situ. There were three hips which underwent staged revision for deep infection, one of which was performed at another centre and all at least nine years after

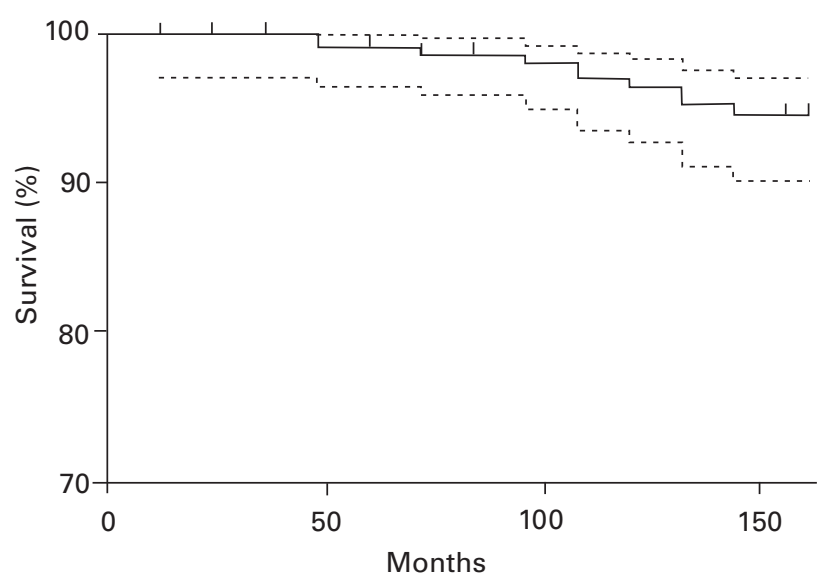

Fig. 5

Graph showing survivorship curve showing the worst case scenario with revision for any cause as the endpoint.

operation. Two patients grew coagulase negative Staphylococcus and the third had sterile cultures. Two underwent successful revision surgery but the third required an excision arthroplasty. Currently, no hips under review are awaiting revision.

Surgeon grading. A third of the THRs in our series were undertaken by trainee surgeons (40 operations). There was no significant difference in the Barrack grading, varus/ valgus orientation or any other post-operative radiological criteria, when comparing consultant surgeons with trainees (two revisions of 40 cases). Of the nine hips revised for any cause, only two of the primary THRs were performed by trainee surgeons.

Survivorship. Survivorship curves and life-tables were constructed for different endpoints. Survival of the femoral component with revision for any cause as an endpoint was $94.9 \%$ at 13 years (Fig. 3); with revision of the Elite Ogee acetabular component for aseptic loosening as an endpoint the survival was $97.1 \%$ (Fig. 4) and the worst case scenario with revision for any reason to include the patient lost to follow-up showed survival of $96.6 \%$ at 13 years (Fig. 5).

\section{Discussion}

Our study is the first to show the findings at a minimum follow-up of ten years for the Exeter Universal femoral component in a District General Hospital. It is also the first to demonstrate a successful combination of this femoral component with the Elite Ogee acetabular component which was used in all but six of the THRs.

No femoral component required revision for loosening, giving comparable results with those of the originating centre $^{4}$ and those from a teaching unit, ${ }^{5}$ but with a longer mean follow-up. Unlike these earlier studies, we did lose one patient to follow-up, but even considering the worst-case scenario with revision of the THR for any reason the survival was $94.4 \%$ (Fig. 5 ). 
The femoral component was shown to have few radiolucent lines at the cement-bone interface, confirming the observation by the Bristol group ${ }^{5}$ who also used secondgeneration cementing techniques. All the femoral components in our series were found to subside to an extent, which seemed to be linked to the Barrack grading. In our series, of those available for radiological review, 42 hips $(34.7 \%)$ were inserted in more than $2^{\circ}$ of varus or valgus. Historically, malposition of the femoral component has been considered to be detrimental to outcome with a reported increase in the risk of femoral fracture and aseptic loosening. ${ }^{17}$ However, the Exeter femoral component has been shown to subside into valgus and internal rotation because of the rounded shoulder of the implant, ${ }^{18}$ but the taper-slip principle depends on subsidence to ensure stability. ${ }^{19}$ Our results support the conclusion of the Bristol group ${ }^{5}$ that although the cementing technique does have a bearing on the behaviour of the stem the design is very tolerant of a less-than-perfect cement mantle.

Only one femoral component had a non-progressive fracture of the cement mantle, which was similar to previous studies. ${ }^{4,5}$ Cortical hypertrophy was seen in 14 of 121 hips, which is a slightly higher rate than has been previously published. ${ }^{4,5}$ The extent of the hypertrophy was minor in all cases but seemed to reflect the Barrack cement grading. However, this was not matched to poor outcome, diminished function or unsatisfactory pain scores. We had no cases of femoral osteolysis which agreed with the Exeter series, ${ }^{4}$ but contrasted with the Bristol group, ${ }^{5}$ in which most poor results could be attributed to the use of a variety of acetabular components with high rates of wear.

Despite using CMW cement in 228 hips, for which the Swedish hip registry reports a risk ratio for aseptic loosening of $0.73,{ }^{20}$ which is higher than that of other commonly-used bone cements, there was no increase in the rate of aseptic loosening of the femoral component compared with the Exeter and Bristol groups, who used Simplex and Palacos cement with risk ratios of 0.60 and 0.51 , respectively. The Exeter femoral component has even performed favourably in comparison with other components such as the Charnley component when paired with Boneloc cement which has a risk ratio of 1.0 at five years. ${ }^{21,22}$ This further supports the contention that the design of the Exeter femoral component allows for migration without affecting its inherent stability or longevity.

Our results appear to agree with those of Fender, van der Meulen and Gregg ${ }^{23}$ who found no difference in outcome between consultant and trainee surgeons with the Charnley THR. However, another report identified considerably more revisions when comparing trainees with consultants undertaking cemented THR. ${ }^{24}$ Nevertheless our series concerns the first 230 Exeter THRs performed in this hospital, suggesting that the outcome is not dependent on the experience of the surgeon.
The Elite Ogee acetabular component was used in 218 $(94.8 \%)$ of the THRs undertaken in our study. The National Joint Registry reports this to be the second most commonly used cemented acetabular component in England and Wales in 2007..$^{25}$ The Exeter femoral component and Ogee component were found to be the most common combination of components matched from different manufacturers; the Swedish hip registry ${ }^{6}$ shows a survival of $98.9 \%$ at five years for this combination. Our survivorship for the Elite Ogee component was $97.1 \%$ at a mean follow-up of 11.2 years. Although $59 \%$ of the acetabular components had one or more lucent areas in the zones described by DeLee and Charnley, ${ }^{14}$ no acetabular component had migrated and there were no areas of focal pelvic osteolysis seen in the 121 radiographs analysed. The survivorship for this component with the Charnley femoral component has been reported as $97 \%$ and $100 \%{ }^{26,27}$ Together, our results and those from the Swedish hip registry ${ }^{6}$ suggest that the Exeter femoral component and Elite Ogee acetabular component are a good combination.

When the database from which our data were extracted was established in 1994 it did not incorporate a rigorous collection of all post-operative complications which might not result in a revision of the implant. Some data were collected on dislocations, thromboembolic events and other medical complications, but these were not sufficiently robust for critical analysis. The database and patient questionnaire have since been altered to collect this information. Additionally, it should be noted that the modified HHS used throughout has been modified since it did not include the component of the patient's examination. Because of a lack of funding initially it was not possible to recall each patient for an annual examination to complete the modified HHS. As an alternative, postal or telephone enquiries were carried out. We accept that the lack of complete scores is a limitation of our study and prevents comparison with the findings of other publications.

Our results, produced from a District General Hospital with a mixture of grades of operating surgeon, are excellent and compare with those of the originating centre at a minimum follow-up of ten years. We have also demonstrated that the combination with the Ogee acetabular component is successful and, together, these components produce a reliable THR which can be used both by experienced and trainee surgeons.

\section{Supplementary material}

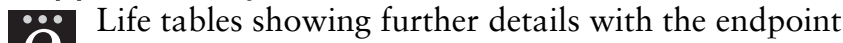
of revision for any cause, endpoint of revision of the Elite Ogee acetabular component and endpoint of revision for "worst case scenario" are available with the electronic version of this article on our website at www.jbjs.org.uk

We wish to thank Mr A. August and Mr S. Sjolin for allowing us to report their patients and $\mathrm{Mr} \mathrm{M}$. Porteous for guidance during the preparation of the manuscript. In addition, we thank Mr B. Ollivere for assistance with the statistics and Mrs V. Hamilton for her invaluable assistance in maintaining the database.

No benefits in any form have been received or will be received from a commercial party related directly or indirectly to the subject of this article. 


\section{References}

1. Fowler JL, Gie GA, Lee AJ, Ling RS. Experience with the Exeter total hip replacement since 1970. Clin Orthop 1988;19:477-89.

2. Rockborn P, OIsson SS. Loosening and bone resorption in Exeter hip arthroplasties: review at a minimum of five years. J Bone Joint Surg [Br] 1993;75-B:865-8.

3. Howie DW, Middleton RG, Costi K. Loosening of matt and polished cemented femoral stems. J Bone Joint Surg [Br] 1998;80-B:573-6.

4. Williams HD, Browne G, Gie RS, et al. The Exeter universal cemented femoral component at 8-12 years: a study of the first 325 hips. J Bone Joint Surg [Br] 2002;84B:324-34.

5. Hook S, Moulder E, Yates PJ, et al. The Exeter Universal stem: a minimum ten-year review from an independent centre. J Bone Joint Surg [Br] 2006;88-B:1584-90.

6. No authors listed. The Swedish Hip Arthroplasty Register 2005. http:// www.jru.orthop.gu.se (date last accessed 15 October 2008).

7. Harris WH. Traumatic arthritis of the hip after dislocation and acetabular fracture: treatment by mold arthroplasty. J Bone Joint Surg [Am] 1969;51-A:737-55.

8. Johnston RC, Fitzgerald RH Jr, Harris WH, et al. Clinical and radiographic evaluation of total hip replacement: a standard system of terminology for reporting results. J Bone Joint Surg [Am] 1990;72-A:161-8.

9. Barrack RL, Mulroy RD Jr, Harris WM. Improved cementing techniques and femoral component loosening in young patients with hip arthroplasty: a twelve year radiographic review. J Bone Joint Surg [Br] 1992;74-B:385-9.

10. Gruen TA, McNeice GM, Amstutz HC. "Modes of failure" of cement stem-type femoral components: a radiographic analysis of loosening. Clin Orthop 1979;141:17-27.

11. Kobayashi S, Takaoka K, Saito N, Hisa K. Factors affecting aseptic failure of fixation after primary Charnley total hip arthroplasty: multivariate survival analysis. $J$ Bone Joint Surg [Am] 1997;79-A:1618-27.

12. Engh CA, Bobyn JJ, Glassman AH. Porous-coated hip replacement: the factors governing bone ingrowth, stress shielding, and clinical results. J Bone Joint Surg [Br] 1987;69-B:45-55.

13. Brooker AF, Bowerman JW, Robinson RA, Riley LH Jr. Ectopic ossification following total hip replacement: incidence and a method of classification. $J$ Bone Joint Surg [Am] 1973;55-A:1629-32.
14. DeLee JG, Charnley J. Radiological demarcation of cemented sockets in total hip replacements. Clin Orthop 1976;121:20-32.

15. Latimer HA, Lachiewicz PF. Porous-coated acetabular components with screw fixation: five to ten-year results. J Bone Joint Surg [Am] 1996;78-A:975-81.

16. Murray DW, Carr AJ, Bulstrode C. Survival analysis of joint replacements. J Bone Joint Surg [Br] 1993;75-B:697-704.

17. Ebramzadeh E, Sarmiento A, McKellop HA, Llinas A, Gogan W. The cement mantle in total hip arthroplasty: analysis of long-term radiographic results. J Bone Joint Surg [Am] 1994;76-A:77-87.

18. Glyn-Jones S, Gill HS, Beard DJ, McLardy-Smith P, Murray DW. Influence of stem geometry of the stability of polished tapered cemented femoral stems. J Bone Joint Surg [Br] 2005;87-B:921-7.

19. Shen G. Femoral stem fixation: an engineering interpretation of the long-term outcome of the Charnley and Exeter stems. J Bone Joint Surg [Br] 1998;80-B:754-6.

20. Malchau H, Herberts P, Soderman P, Oden A. Prognosis of total hip replacement: update and validation of results from the Swedish National Hip Arthroplasty Register 1979-1998. Orlando: American Academy of Orthopaedic Surgeons, 2000.

21. Thomsen PB, Bøvling S, Jacoby B, Hansen TB. Aseptic loosening of Boneloc cemented Exeter total hip replacement: a 5 year follow-up of the first 100 hips. Hip International 2000;10:102-7.

22. Furnes O, Lie SA, Havelin LI, Vollset SE, Engesaeter LB. Exeter and Charnley arthroplasties with Boneloc or high viscosity cement: comparison of 1,127 arthroplasties followed for 5 years in the Norwegian Arthroplasty Register. Acta Orthop Scand 1997;68:515-20.

23. Fender $\mathbf{D}$, van der Meulen JHP, Gregg PJ. Relationship between outcome and annual surgical experience for the Charnley total hip replacement: results from a regional hip register. J Bone Joint Surg [Br] 2003;85-B:187-90.

24. Marston RA, Cobb AC, Bentley G. Stanmore compared with Charnley total hip replacement: a prospective study of 413 arthroplasties. J Bone Joint Surg $[B r]$ 1996;78-B:178-84.

25. No authors listed. National Joint Registry. 4th Annual Report.pp112. http:// www.njrcentre.org.uk (date last accessed 28th October 2008).

26. Wroblewski BM, Siney PD. Charnley low friction arthroplasty of the hip: long term results. Clin Orthop 1993;292:191-201.

27. Garellick G, Malchau H, Herberts P. Survival of hip replacements: a comparison of a randomised trial and a registry. Clin Orthop 2000;375:157-67. 